\title{
A ATUAÇÃO DO SERVIÇO NACIONAL DE INFORMAÇÃO (SNI) NA UNIVERSIDADE FEDERAL DA PARAÍBA (UFPB): A VIGILÂNCIA SOBRE OS DIRIGENTES UNIVERSITÁRIOS (1976-1985)
}

\author{
Paulo Giovani Antonino Nunes ${ }^{1}$
}

\section{Introdução}

De acordo com Alves (1989), com o golpe civil-militar, uma das primeiras medidas de institucionalização do novo governo foi a criação do Serviço Nacional de Informação (SNI). Ele foi criado formalmente pelo Decreto-Lei $\mathrm{n}^{\circ} 4.341$, de 13 de junho de 1964, como órgão de assessoramento do Executivo, responsável - não perante ao Congresso Nacional - mas ao Conselho de Segurança Nacional e ao Presidente da República. Esse órgão teve como primeiro presidente seu idealizador, o general Golbery do Couto e Silva, que "dezessete anos depois de tê-lo criado viria a chamá-lo de 'monstro'”. ${ }^{2}$ Segundo Alves,

A lei determinava explicitamente que o SNI deveria colaborar com o Conselho de Segurança Nacional em 'todas as questões afetas à Segurança Nacional'. Declarava que seu principal objetivo seria 'coletar e analisar informações pertinentes à Segurança Nacional, à contra-informação e à informação sobre questões de subversão interna. Na prática, o SNI tornou-se um poder político de facto, quase tão importante quanto o do próprio Executivo. ${ }^{3}$

Segundo Fico (2001), quando se tem contato com o pensamento da comunidade de informações, a primeira reação é o riso. Pois, na produção dos documentos dos órgãos, a preocupação com a força do "inimigo" parece excessiva e o jargão dos militares envolvidos emprestam aos documentos um tom grandiloquente e tecnicista de algum modo incompatível com a real dimensão do problema. Por fim, de acordo com o referido autor, o tratamento ideológico é de tal forma precário, que soa como o mais elementar "falseamento da realidade". Mas, Fico, alerta que, para além do caráter grotesco,

(...) ao longo dos anos, o Serviço Nacional de Informações (SNI) constituiu-se em fonte bastante profissional de informações para os generais-presidentes, permanecendo quase sempre nos níveis subalternos as avaliações equivocadas, filtradas que eram, naturalmente, pelos escalões superiores e mais habilitados. Desse modo, a comunidade de informações gerou situações muito sérias, com consequências gravíssimas para a sociedade brasileira. É necessário, portanto, compreendê-lo em profundidade, pois o folclore sobre as 'trapalhadas' pode ocultar a verdadeira dimensão do problema. ${ }^{4}$

Em 1970, o governo militar, visando aperfeiçoar o sistema de informações, institui o Sistema Nacional de Informações (Sisni). Este passou a ser integrado pelo Serviço Nacional de Informações (SNI), pelos Sistemas Setoriais de Informações dos Ministérios Civis, pelos Sistemas Setoriais de Informações dos Ministérios Militares, pelo Subsistema de Informações Estratégicas Militares (SUSIEM)

\footnotetext{
${ }^{1}$ Doutor em História do Brasil pela Universidade Federal de Pernambuco (UFPE). Realizou estágio pós-doutoral junto ao Programa de Pós-Graduação em História da Universidade Federal de Minas Gerais (UFMG). Professor Associado do Departamento e do Programa de Pós-Graduação em História da Universidade Federal da Paraíba (UFPB), Campus I, JoãoPessoa, e-mail: pauloantoninonunes@hotmail.com.

${ }^{2}$ GASPARI, Elio. A ditadura envergonhada. São Paulo: Companhia das Letras, 2002, p. 153.

${ }^{3}$ ALVES, Maria Helena Moreira. Estado e oposição no Brasil (1964-1984). 4 ed. Petrópolis: Vozes, 1989, p. 72-73.

${ }^{4}$ FICO, Carlos. Como eles agiam: Os subterrâneos da ditadura militar: espionagem e polícia política. Rio de Janeiro: Record, 2001, p. 74-75.
} 
e por outros órgãos setoriais. De acordo com Fico,

O SNI era o órgão central do Sisni. Seu chefe tinha status de ministro de Estado e assessorava diretamente o presidente da República. Competia-lhe superintender $e$ coordenar as atividades de informações em todo o território nacional. Paulatinamente, o Serviço foi buscando recolher informações também no exterior, sobretudo em relação aos países da América Latina. ${ }^{5}$

Os Sistemas Setoriais de Informações dos Ministérios Civis eram constituídos pelos órgãos de informações dos respectivos ministérios e das autarquias, fundações e empresas estatais vinculadas. $\mathrm{O}$ órgão central de informações de um ministério civil era a sua Divisão de Segurança e Informações.

O papel das DSIs era assessorar os titulares dos ministérios no processo de tomada de decisão e em questões de segurança. Mas elas funcionavam sob um duplo comando: eram subordinadas ao ministro respectivo, nominalmente seu chefe, porém, ao mesmo tempo, eram coordenadas pelo CSN até 1970, e a partir daí pelo SNI. Os diretores das DSIs em geral eram oficiais superiores reformados das Forças Armadas coronéis ou generais do Exército, brigadeiros da Aeronáutica. ${ }^{6}$

Em cada órgão importante de administração pública existia uma Assessoria de Segurança e Informações (ASI), em alguns casos, também chamada de Assessoria Especial de Segurança $e$ Informações (AESI). ${ }^{7}$ Entre as várias "Assessorias" criadas, uma das mais importantes foi a das instituições de ensino superior, especialmente nas universidades públicas, com objetivo de vigiar o meio acadêmico, considerado um foco de subversão. Segundo Motta,

A partir de 1970, o governo criou órgãos de informação dentro das universidades, as Assessorias Especiais de Segurança e Informações (Aesis ou ASIs), que fariam parte da vida acadêmica nos anos seguintes. Na lógica dos responsáveis pela área de segurança e repressão, o expurgo de professores e estudantes inconvenientes deveria ser seguido de constante vigilância para impedir o 'retorno' das ameaças. Daí a ideia de criar assessorias de informação dentro das instituições de ensino superior: elas seriam um 'braço' do Sistema Nacional de Informações (Sisni): funcionariam como uma espécie de correia de transmissão, fazendo chegar determinações e pressões políticas provenientes dos escalões superiores; e, ao mesmo tempo, vigiariam a comunidade universitária e os próprios dirigentes, nem sempre fiéis aos desígnios do regime militar. ${ }^{8}$

Os Sistemas Setoriais de Informações dos Ministérios Militares eram específicos das Forças Armadas - Marinha, Exército e Aeronáutica. No âmbito do sistema da Marinha, o principal órgão ${ }^{9}$ era o Centro de Informações da Marinha (CENIMAR); no Exército, o Centro de Informação do Exército (CIE), e na Aeronáutica, o Centro de Informações de Segurança Aeronáutica (CISA). Segundo Fico,

Os órgãos militares de informações também realizavam operações de segurança, isto é, eram 'executantes', podendo ser caracterizados como 'órgãos mistos', de informações e de segurança. Diferentemente das DSI e, em boa medida, do próprio SNI, o CIE, o CENIMAR e o CISA também patrocinavam 'operações', ou seja, saíam à rua para prender pessoas que seriam interrogadas, sendo conhecidos diversos relatos

\footnotetext{
${ }^{5}$ FICO, Como eles agiam..., p. 81.

${ }^{6}$ MOTTA, Rodrigo Patto Sá. As universidades e o regime militar: cultura política brasileira e modernização autoritária. Rio de Janeiro: Zahar, 2014. p, 194-193.

${ }^{7}$ Essas agências foram denominadas incialmente Assessorias Especiais de Segurança e Informações (Aesis), porém, após nova reformulação do sistema, em 1975, a denominação oficial passou a ser ASI. Ver. MOTTA. As universidades e o regime militar:.. p. 195.

${ }^{8}$ MOTTA. As universidades e o regime militar:.. p. 193.

${ }^{9}$ Para uma relação completa dos órgãos das três Forças e da montagem de todo sistema de espionagem e repressão, ver FICO. Como eles agiam... 2001; ANTUNES, Priscila Carlos Brandão. SNI \& ABIN: uma leitura da atuação dos Serviços Secretos brasileiros ao longo do século XX. Rio de Janeiro: FGV, 2001; FIGUEIREDO, Lucas. Ministério do Silêncio: A história do serviço secreto brasileiro de Washington Luís a Lula (1927-2005). Rio de Janeiro: Record, 2005.
} 
de presos políticos torturados por agentes desses órgãos. ${ }^{10}$

Os Sistemas Setoriais de Informações dos Ministérios Militares, pelo Subsistema de Informações Estratégicas Militares (SUSIEM), era o órgão responsável por tratar as informações relacionadas às operações militares. Ele era coordenado pelo ministro-chefe do Estado-Maior das Forças Armadas (EMFA).

De acordo com Fico (2001), o que o Sisni entendia como "Outros Órgãos Setoriais de Informações" eram assessorias de informações situadas em importantes esferas da administração pública ou em empresas estatais.

Diante do que foi exposto, este texto pretende analisar a produção de informações feita pelo Serviço de Nacional de Informações (SNI) referentes a membros da comunidade acadêmica da Universidade Federal da Paraíba (UFPB), com ênfase nos dirigentes universitários.

Para a consecução desse objetivo, tomamos como base fontes primárias impressas, especificamente, os documentos dos do Fundo SNI - Agência Pernambuco - arquivados no acervo da Comissão Estadual da Verdade e Preservação da Memória do Estado Paraíba. ${ }^{11}$ A referida Agência desenvolvia seu trabalho nos estados de Pernambuco, Paraíba, Rio Grande do Norte e Alagoas.

Os documentos do SNI são o que Caroline Silveira Bauer e René E. Gertz chamam de "fontes sensíveis". Segundo os referidos autores,

Esses documentos afetam, de forma direta, a sociedade em que foram produzidos $e$ recuperados (Estado, agentes da repressão, vítimas, familiares, organizações de Direitos Humanos, Forças Armadas), principalmente porque, no caso das ditaduras militares, seus protagonistas ainda estão vivos e por constituírem fatos do passado recente dessas sociedades. Isso traz à tona a discussão sobre privacidade $e$ preservação da intimidade das pessoas. Além disso, esses arquivos possuem, somado ao valor histórico e judicial, grande valor para a definição da memória histórica e para a constituição da identidade. ${ }^{12}$

Nesse contexto, pós ditadura militar e após longa luta pela abertura de parte dos arquivos da mesma,

(...) os documentos que compõem os acervos provenientes das forças repressivas servem (...) para atividades opostas à sua origem - produzidos para coordenar ações repressivas, agora podem ser usados para compensar vítimas por arbitrariedades $e$ violações de seus direitos. ${ }^{13}$

\footnotetext{
${ }^{10}$ FICO. Como eles agiam..., p. 92.

${ }^{11} \mathrm{Na}$ pesquisa empírica, tivemos a colaboração de Elissandra Maria Costa Dias, aluna da graduação em História da UFPB e b bolsista de Iniciação Científica no projeto por nós coordenado, intitulado, "A sociedade civil sob vigilância: a atuação do Serviço Nacional de Informação (SNI) na Paraíba (1964-1985)".

${ }^{12}$ BAUER, Caroline Silveira.; GERTZ, René E. "Fontes sensíveis na história recente". In. PINSKY, Carla Bassanezi; LUCA, Tania Regina de. (Orga.) O historiador e suas fontes. São Paulo: Contexto, 2015, p. 178.

${ }^{13}$ BAUER; GERTZ. Fontes sensíveis na história recente..., p. 178.
} 


\section{UFPB: Repressão e criação do Sistema de Informação}

A Universidade da Paraíba foi criada pela Lei Estadual 1.366, de 02 de dezembro de 1955, como resultado da junção de algumas escolas superiores. Posteriormente, com a sua federalização, aprovada e promulgada pela Lei $\mathrm{n}^{\circ}$. 3.835 de 13 de dezembro de 1960, foi transformada em Universidade Federal da Paraíba (UFPB), incorporando as estruturas universitárias existentes nas cidades de João Pessoa e Campina Grande. A partir de sua federalização, a UFPB se constituiu em uma crescente estrutura multicampi. ${ }^{14}$ No início de 2002, a UFPB passou pelo desmembramento de quatro dos seus sete campi. A Lei $n^{\circ} 10.419$ de 9 de abril de 2002 criou, por desmembramento da UFPB, a Universidade Federal de Campina Grande (UFCG), com sede em Campina Grande. A partir de então, a UFPB ficou composta legalmente pelos campi de João Pessoa (capital), Areia $e$ Bananeiras, passando os demais campi (Campina Grande, Cajazeiras, Patos e Sousa) a serem incorporados pela UFCG. Em 2005 foi criado mais um campus, no Litoral Norte do Estado, abrangendo os municípios de Mamanguape e Rio Tinto.

Após o golpe civil-militar de 1964 e durante toda duração da ditadura militar, o corpo acadêmico da UFPB sofreu muito com a repressão. O reitor da Universidade Federal da Paraíba, professor Mário Moacyr Porto, foi afastado do cargo no imediato pós-golpe pelos militares locais, que acreditavam ter evidências do seu envolvimento com a esquerda.

Segundo informe dos órgãos de inteligência ${ }^{15}$, o reitor teria apoiado atividades dos comunistas e facilitado o proselitismo de esquerda. Entre outras coisas, ele foi acusado de financiar viagens de estudantes à URSS e também publicações subversivas (um jornal estudantil). Uma evidência serviu de prova cabal de sua 'culpa' aos olhos dos militares: "Foi agraciado com a comenda de honra da União Internacional dos Estudantes, cuja sede é Praga". ${ }^{16}$

Em seu lugar, foi nomeado como interventor o professor de Medicina e ex-oficial do Exército, Guilherme Martins Alves, que depois foi eleito pelo Conselho Universitário, onde exerceu mandatos sucessivos até o ano de 1971.

O setor estudantil também foi muito perseguido. As direções das entidades estudantis universitárias sofreram intervenções. Muitos estudantes tiveram suas matrículas suspensas de forma definitiva ou temporária. ${ }^{17}$

Na UFPB, ainda sob o comando de Guillardo Alves, foram excluídas dezenas de estudantes em fevereiro de 1969 , alguns dias antes da promulgação do 477 . No ofício reservado expedido para cumprimento da ordem alegava-se seguir recomendações das chefias militares da área. A maioria dos punidos ficou impedida de estudar na universidade entre um $e$ dois anos, mas alguns foram excluídos de modo definitivo. ${ }^{18}$

Também houve perseguição a professores universitários com ou demissões ou contratos trabalho não renovados.

Na UFPB, a mesma reitoria que excluiu dezenas de estudantes e determinou intervenção nos diretórios estudantis expurgou também o corpo docente, afastando cerca de vinte professores. Em março de 1969, no reinício das aulas, saiu a decisão de romper o contrato de trabalho desse grupo de docentes, que provavelmente ainda não

\footnotetext{
${ }^{14}$ Ela passou a ser composta de sete campi implantados nas cidades de João Pessoa, Campina Grande, Areia, Bananeiras, Patos, Sousa e Cajazeiras.

${ }^{15}$ Esse informe foi enviando ao SNI pela Assessoria de Segurança e Informações da UFRN, em março de 1975, e historiava os acontecimentos da UFPB. Ver MOTTA. As universidades e o regime militar:.. p, 368.

${ }^{16}$ MOTTA. As universidades e o regime militar:.. p, 42.

17 Para uma relação completa dos expurgos de estudantes na UFPB. Ver. COMISSÃO ESTADUAL DA VERDADE E PRESERVAÇÃO DA MEMÓRIA DO ESTADO DA PARAÍBA. Relatório Final. João Pessoa, A União, 2017.

${ }^{18}$ MOTTA. As universidades e o regime militar:.. p, 157.
} 
tinham estabilidade. ${ }^{19}$

Com relação à vigilância da comunidade universitária na UFPB, foi criado, logo após o golpe civilmilitar, o Serviço de Segurança e Informações (SSI), que passou por uma reestruturação com a criação da Divisão de Segurança e Informações (DSI), no início dos de 1970. Na UFPB, a fundação oficial da Aesi se deu em março de 1971. Segundo Motta,

Na UFPB, cujo reitor 'anfíbio' (o militar e professor Guilardo Martins Alves) também já demonstrara seu empenho 'purificador', no início de 1969 já estava em funcionamento um Serviço de Segurança e Informação. Essas experiências precursoras podem ter estimulado e inspirado a criação de agência de informação em todo o sistema universitário, o que só aconteceu efetivamente em 1971. Graças a seu pioneirismo, a Aeisi/UFPB foi das mais bem organizadas e atuantes na primeira metade dos anos 1970, quando seu regimento interno servia de modelo para agências congêneres. ${ }^{20}$

O referido regime interno da Aesi/UFPB, que pode ter servido de modelo para outras agências de informação no âmbito das universidades, foi aprovada pelo reitor Guilardo Martins Alves no dia 19 de março de 1971, com as seguintes competências:

I - No que se refere à Segurança Nacional:

a) Coletar dados necessários aos estudos e planejamentos relativos à Segurança Nacional, particularmente aos que se referem à mobilização nacional, de conformidade com a orientação recebida da Divisão de Segurança e Informações do Ministério da Educação e Cultura.

b) realizar outras missões e tarefas atribuídas pelo Reitor, coerentes com a finalidade do órgão.

II- No que se refere às informações e contra-informações:

a) Coordenar e supervisionar a execução do Plano Setorial de Informações, consoante com as instruções emanadas da DSIEC e do Reitor da UFPB;

b) produzir informações:

- necessárias às decisões do Reitor da UFPB.

- para atender às determinações contidas no Plano Setorial de Informações (PSI desmembramento);

c) encaminhar a DSIEC as informações necessárias, segundo a periodicidade estabelecida no PSI e, em documento especial, aquelas que, pelo Princípio da Oportunidade, devem ser do conhecimento dos clientes principais da DSIEC;

d) obter informações que caracterizem os antagonismos atuais ou potenciais, existentes na área de influência da Universidade, bem como os grupos do de pressão, que os explorem e que possam afetar à execução da Política Ministerial;

e) estudar e dar parecer sobre assuntos inerentes às atribuições do órgão, quando lhe forem submetidas pelo Reitor da UFPB;

f) executar outras missões referentes à Segurança Nacional $e$ às informações que lhe forem atribuídas pelo Reitor;

g) acompanhar o desenvolvimento da Política Nacional no seu amplo sentido;

h) criar uma correta mentalidade de informações, tendo viva a ideia do Desenvolvimento com informações para melhor Decisão;

i) desenvolver o serviço de contra-informações, nos diversos campos ao seu alcance, tais como: teatro - rádio - cinema - revista - etc.;

j) informar sobre assuntos que transcendem a esfera da Universidade. ${ }^{21}$

A estrutura da Aesi/UFPB contava com uma direção composta pela Chefia (CH/AESI) e Auxiliar

\footnotetext{
${ }^{19}$ MOTTA. As universidades e o regime militar:.. p, 165. Para uma relação completa dos expurgos de professores na UFPB, ver COMISSÃO ESTADUAL DA VERDADE...

${ }^{20}$ MOTTA. As universidades e o regime militar:.. p, 196.

${ }^{21}$ COMISSÃO ESTADUAL DA VERDADE..., p. 169-170.
} 
(A/AESI), pela Seção de Segurança e Informações (SSI/AESI), e pela Seção Administrativa (AS/AESI). ${ }^{22}$ Durante muito tempo, o cargo de chefia foi exercido pelo sargento do Exército e depois professor da UFPB, no curso de Farmácia, Ediláudio Luna de Carvalho. A atuação da Aesi/UFPB foi apontada como um dos problemas pelo reitor Lynaldo Cavalcanti de Albuquerque, nomeado em 1975. Em entrevista concedida ao Projeto História da UFPB/NDIHR, em setembro de 1990, perguntado sobre quais os problemas encontrou ao assumir a reitoria, indicou, entre outros:

Agora, a atividade meio, sim, tinha um problema sério, porque eu estava entrando numa Universidade que vinha com 7 anos de Reitorado de Guilardo e 4 anos de $\mathrm{dr}$. Humberto no regime militar, em que havia uma DSI forte, havia um SNI forte, muito presente nas Universidades, embora isso tenha sido amenizado na gestão Geisel pelo Ney Braga. ${ }^{23}$

Na mesma entrevista, perguntado se Aesi funcionava na sua época na Universidade, respondeu:

Como! Quer dizer, ela funcionava muito, a Paraíba foi uma das Assessorias que mais funcionaram, tinha o Ediláudio, nunca mais vi, não sei onde é que anda, mas era um aluno de Farmácia e sargento do Exército que depois foi professor e foi assessor de Segurança do Reitor Guilardo, e participou daquele processo de afastamento de alunos e de professores ${ }^{24}$, aquela coisa todinha, e continuou com o dr. Humberto [...] Agora eu não, disse logo a Orlando que ia ser meu vice, 'Orlando, você vai assumir por 3 meses', [...] eu só lhe peço uma coisa, afaste Ediláudio [...], eu quero chegar lá com essa área limpa'. Aí ele colocou o general Nogui Villar de Aquino. Era um general da reserva, uma pessoa ligada a uma família ilustre, com muito conceito na área militar, inclusive para o lado do general Bandeira, mas se revelou muito compreensivo e me ajudou bastante nessa luta que foi expansão do corpo docente, sem levar muito em conta os antecedentes políticos. ${ }^{25}$

Então, como podemos perceber pela fala do próprio reitor Lynaldo Cavalcanti, a ASI-UFPB, funcionava de forma muito ativa, e ele teria tido a pretensão de diminuir essa interferência, mas como iremos verificar na sequência do texto, a vigilância continuou, feita por ela ou outros órgãos de informação do regime e um dos alvos foi o próprio reitor.

\section{Vigilância aos dirigentes universitários}

De acordo com Motta (2014), nos anos de 1970, no âmbito da Reforma Universitária promovida pelo governo militar pelo Decreto $\mathrm{N}^{\circ} 5.540$, e no clima do "milagre econômico" surgiu a figura dos reitores "empreendedores", que se aproveitaram das oportunidades de investimento nas universidades públicas. Entre outros, dois são destacados pelo referido autor: Zeferino Vaz, da Unicamp e Lynaldo Cavalcanti de Albuquerque da UFPB. Segundo Motta,

\footnotetext{
${ }^{22}$ COMISSÃO ESTADUAL DA VERDADE..., p. 170.

${ }^{23}$ FERREIRA, Lúcia de Fátima Guerra.; FERNANDES, David. (org.). UFPB 50 Anos. João Pessoa: Editora Universitária/UFPB, 2006, p. 105.

${ }^{24} \mathrm{De}$ alguma forma, Lynaldo Cavalcanti também esteve ligado ao processo de afastamento de estudantes da UFPB, pois 1964, quando da proibição provisória da matrícula dos estudantes que tinham participado da Ocupação da Faculdade de Direito, antes do golpe, ele fazia parte do Conselho Universitário da instituição que aprovou a medida. Ver: COMISSÃO ESTADUAL DA VERDADE..., p. 20.

${ }^{25}$ FERREIRA; FERNANDES. UFPB 50 Anos..., p. 105.
} 
Os dois foram reitores dinâmicos e administradores competentes. Com bons contatos nas esferas de poder, conseguiram integrar as respectivas universidades na onda modernizadora e reformadora do período. Embora desfrutassem da confiança política do regime militar, ambos foram capazes também de conquistar o respeito de professores com ideias oposicionistas e mesmo de esquerda. ${ }^{26}$

Lynaldo Cavalcanti foi reitor da UFPB entre 1976 e 1980. Ele se caracterizou pela flexibilidade e tolerância ideológica, pois contratou muitos professores "suspeitos" aos olhos dos órgãos de segurança, que consideravam o novo reitor leniente em relação aos riscos à "segurança nacional". Segundo Motta,

No início de 1977, a Seção de Informações do IV Exército mandou documento ao SNI reclamando que, desde o início de 1976, a UFPB vinha contratando vários professores com registros políticos comprometedores. $\mathrm{E}$ as dores de cabeça dos agentes repressivos pioraram nos anos seguintes, pois a universidade se tornou centro importante na área de ciências humanas e sociais exatamente em decorrência dessas contratações. ${ }^{27}$

Ainda de acordo com Motta (2014), do ponto de vista da expansão da UFPB, Lynaldo Cavalcanti seguiu os passos do reitorado de Guilardo Martins, pois durante a gestão deste houve um crescimento do corpo docente e discente, sendo que os alunos passaram de 1.625 em 1964 a 5.620 em 1971. Lynaldo Cavalcanti deu continuidade e ampliou o ritmo dessa expansão, ajudando a transformar a UFPB em uma das principais universidades do Nordeste e uma das maiores do país, com 21 mil alunos e 2.600 professores, em 1980. No entanto, este mudou parcialmente a orientação repressiva da reitoria da UFPB, interessado em atrair profissionais competentes e dinâmicos para a universidade, independente das convicções políticas. Para Motta,

A estratégia era crescer quantitativamente e qualitativamente, não só com uma política agressiva de contratações de professores vindos de outras regiões do país e mesmo do exterior, mas também criando laboratórios, grupos de pesquisa e cursos de pósgraduação. O prestígio alcançado pela UFPB nos anos 1980 deveu-se em grande parte ao sucesso dessa estratégia de contratações, que levou muitos pesquisadores de talento para João Pessoa e Campina Grande. ${ }^{28}$

Apesar de algumas críticas que circularam no meio acadêmico, contra a gestão de Lynaldo Cavalcanti, devido ao fato de, na ânsia de crescimento da instituição, ele ter criado alguns cursos de graduação e pós-graduação frágeis e imaturos, sua imagem de gestor era positiva, inclusive na chamada grande imprensa. Segundo Mota,

Uma matéria da revista Veja em setembro de 1980, por exemplo, elogiava o desempenho do 'liberal' Lynaldo Cavalcanti, que teria transformado a UFPB na principal universidade nordestina, com trinta cursos de pós-graduação e duzentos professores contratados de fora da região, a maioria do Sudeste. A habilidade do reitor era louvada também por ter conseguido transformar o orçamento da universidade no segundo entre as federais: $\mathrm{Cr} \$ 4$ bilhões em 1980. Para que se tenha ideia do significado desse valor, o orçamento do estado da Paraíba era de Cr\$ 7 bilhões. $^{29}$

Segundo Motta (2014), o prestígio do reitor paraibano devia-se também à estreita relação estabelecida com o ministro da Educação, Ney Braga, a quem servira como adjunto do Departamento de Assuntos Universitário do MEC (DAU/MEC). Devido ao programa ambicioso desenvolvido por Lynaldo no seu reitorado na UFPB, este ampliou sua reputação em Brasília e foi considerado pelo

\footnotetext{
${ }^{26}$ MOTTA. As universidades e o regime militar:.. p, 267-268.

${ }^{27}$ MOTTA. As universidades e o regime militar:.., p, 236.

${ }^{28}$ MOTTA. As universidades e o regime militar:.., p, 270.

${ }^{29}$ MOTTA. As universidades e o regime militar:.., p. 270-271.
} 
ministro um dos melhores reitores do Brasil. O reconhecimento alcançado o levou à nomeação para a presidência do Conselho Nacional de Desenvolvimento Científico (CNPq), cargo que ocupou entre 1980 e $1985 .^{30}$

Apesar de todos os serviços prestados no âmbito da Universidade ao regime militar, Lynaldo Cavalcanti foi alvo constante dos Órgãos de Informação (OI) do regime militar, principalmente por sua postura diante da contratação de professores para a UFPB, relativizando a postura ideológica dos mesmos. O objetivo era levantar suspeita sobre Cavalcanti, como podemos ver nesse documento produzido pelo SNI, em 1979, quando ele era reitor da UFPB:

a. (...) Quando do encerramento do Encontro Regional dos Reitores do Nordeste, realizado na UFAL, no período de 18 a 20 Out 77, o nominado foi um dos elaboradores de um documento propondo maior diálogo entre cientistas e o Governo. No período de 22 a 24 Ago 78 esteve na Universidade de SANTA MARIA/RS. Em contato com o Reitor Berblay Galvão, daquela universidade, referiu-se à existência de professores aposentados por leis de exceção e de outros que se encontram no exterior como o sociólogo FERNANDO ANTONIO CARDOSO, o historiador NELSON WERNECK SODRÉ e o Professor DARCY RIBEIRO, dizendo que os mesmos estão fazendo falta ao País. Convidou a direção do SBPC para a realização do encontro daquela entidade no ano de 1979 na Paraíba, oferecendo todo o apoio da UFPB para a efetivação do evento. No período de 25 a 27 Out 78, presidiu um seminário sobre o Sistema Universitário e a Sociedade Brasileira, realizado em JOÃO PESSOA/PB, ocasião em que concordou com uma proposta de extinção das Assessorias de Segurança e Informações das Universidades brasileiras. (...)

Juízo Sintético:

a. Posição: Democrática, em que pese algumas de suas atitudes serem entendidas por setores mais radicais como liberal (sic), alinhando-se entre elas o fato de, em 1971, quando Diretor da Escola Politécnica em Campina Grande/PB, haver convidado o banqueiro e ex-Prefeito cassado daquela cidade, NEWTON VIEIRA RIQUE, a proferir conferência naquele estabelecimento de ensino, abordando tema de sua livre escolha.

b. Ligações Políticas:

Pertence ao grupo do ex-Governador JOÃO AGRIPINO FILHO, considerado o líder dos dissidentes arenistas da PARAÍBA

c. Atitude face à Revolução de 31 Março de 64: Indefinida

d. Atividades subversivas: Não há registros

e. Probidade administrativa: Contratou vários professores com registros negativos $e$ de tendências esquerdistas. Sua administração vem sendo combatida, face a algumas atitudes assumidas, consideradas prejudicais à UFPB. É criticado pela sua política de contratação de professores estrangeiros e de outras Universidades brasileiras, com elevados salários. Mantém bom relacionamento com os seus superiores. Entretanto, há reclamações quanto à distância que procura estabelecer com os seus subordinados. (...). ${ }^{31}$

O professor José Jackson Carneiro de Carvalho entrou no quadro docente da UFPB em 1965 e foi afastado em 1968, por não ter seu contrato de trabalho renovado. Foi reintegrado em 1979, pela lei da Anistia. Em 1981 foi nomeado vice-reitor, durante o mandato de Berilo Ramos Borba. Na ocasião de sua escolha para vice-reitor, o SNI elaborou um prontuário de sua trajetória.

\section{POSIÇÃO POLÍTICO IDEOLÓGICA:}

No período de 1968 a 1970, participou, na qualidade de professor universitário e expadre progressista, de vários movimentos de contestação ao regime, no recinto da exFaculdade de Filosofia/FAFI/PB, fato que impediu a renovação de seu contrato de professor na UFPB. Naquele período, seu nome foi incluído ao lado de nomes como

\footnotetext{
${ }^{30}$ Para mais informações sobre a UFPB e papel do reitorado de Lynaldo Cavalcante de Albuburque, ver RODRIGUES, Cláudio José Lopes. Sociedade e Universidade: Um estudo de caso. João Pessoa: SEC/PB, 1986.

${ }^{31}$ ARE ACE CNF 007/79 I/I. Fundo SNI. Arquivo da Comissão da Verdade e Preservação da Memória do Estado da Paraíba. Fundação Casa de José Américo.
} 
de CHE GUEVARA, numa lista de homenageados dos estudantes esquerdistas paraibanos.

Atualmente mantém um estreito relacionamento com os setores esquerdistas da UFPB, a exemplo da ADUFPB, do qual recebe apoio quando por ocasião de greves $e$ protestos contrários aos interesses do sistema. Geralmente é visto em companhia de elementos contrários à Revolução de Mar 64, como JOSÉ CHASIN e RUBENS PINTO LYRA, que o consideram um aliado dos professores esquerdistas na cúpula universitária.

\section{POSIÇÃO NA UNIVERSIDADE E FORA DELA:}

Na qualidade de Pró-Reitor de Graduação da UFPB, o nominado é tido como pessoa de prestígio junto ao Reitor daquela universidade, em virtude de terem sido companheiros de estudo na UNIVERSIDADE GREGORIANA DE ROMA, onde veio a ordenar-se Padre e, posteriormente, abandonar o sacerdócio. Através dessa amizade, foi convidado pelo Reitor para compor a Lista Sêxtupla de candidatos à vice-Reitoria, tendo sido o mais votado, com 55 sufrágio no primeiro escrutínio e 46 no segundo.

Em virtude de estar desempenhando um cargo de mando na UFPB, tem se mantido discreto no que se refere a revelar publicamente suas tendências esquerdistas, todavia há informes (A-1), de que sempre se encontra com pessoas que comungam com suas ideias políticas, não se excusa de criticar o sistema vigente $e$ as instituições. Tem participado de "pequenas reuniões sociais", compostas de ex-padres que atuam no meio universitário, para debater o papel da Igreja na atualidade, com ênfase ao desempenho de DOM JOSÉ MARIA PIRES, a quem sempre cita elogiosamente em suas palestras.

Critica o processo de anistia, do qual foi um dos beneficiários, pelo fato do anistiado passar pela humilhação de ter que pleitear seu retorno às atividades profissionais.

4. CONCEITO PROFISSIONAL:

a. Dentro da Especialidade - possui licenciatura em Filosofia pela UNIVERSIDADE FEDERAL DE PERNAMBUCO - UFPE. Mestrado e Doutorado em Educação pela UNIVERSIDADE FEDERAL DA BAHIA/UFBA e UNIVERSIDADE FEDERAL DE SÃO PAULO/UFSP, títulos que o credenciam a ser Professor Titular lotado no DEPARTAMENTO DE FUNDAMENTAÇÃO DO CENTRO DE EDUCAÇÃO DA UFPB

b. VISÃO HUMANISTA - O fato de ter tido uma educação metódica em função dos estudos que fez como seminarista e, posteriormente, como padre católico, torna-o um elemento de apurada visão humanística, dedicando às pesquisas filosóficas $e$ educacionais.

5. CAPACIDADE ADMINISTRATIVA:

Tem demonstrado um satisfatório desempenho administrativo.

6. PRINCIPAIS IDEIAS DEFENDIDAS:

Está propenso a defender os princípios de uma universidade aberta e renovada, para tanto admitindo a participação de representações de vários setores universitários. ${ }^{32}$

José Jackson de Carvalho deixou o cargo de vice-reitor para assumir o de secretário de Educação do estado da Paraíba, na gestão do governador Wilson Braga, do Partido Democrático Social (PDS), partido que dava sustentação ao regime militar. Posteriormente, foi eleito reitor da UFPB, em 1984, e novamente foi elaborado um documento sobre sua trajetória, dessa vez pela ASI-UFPB, mas divulgado pelo SNI.

Ago 1968 (1 Gpt E): A partir de 8 Ago 68, eclodiu uma série de manifestações nesta cidade em protestos contra a prisão do líder estudantil VLADIMIR PALMEIRA, na GB. As ditas manifestações culminaram com a ocupação, por parte dos estudantes, do prédio da ex-FaFi. Os Implicados: ... c) Clero: Padres... e JACKSON CARNEIRO. Compareceram a FAFI por diversas vezes para levar aos estudantes que a ocupavam a solidariedade do clero progressista.

19 Out 68: (1 $\left.1^{\circ} \mathrm{Gpt}\right)$ : $\mathrm{Na} 2^{\mathrm{a}}$ quinzena de outubro houve manifestações estudantis na Área com grave perturbação da ordem pública, sendo inclusive necessário a intervenção do Exército. Implicados. c) Professores e JACKSON CARNEIRO. Tiveram

\footnotetext{
${ }^{32}$ ARE ACE CNF 1630/81. Fundo SNI. Arquivo da Comissão da Verdade...
} 
atuação destacada e compactuaram com a baderna estudantil.

Dez 1968 ( $1^{\circ} \mathrm{Gpt}$ E): No convite da turma concluinte do Curso de Filosofia, em 1968, o Padre JACKSON consta como homenageado da turma entre os nomes de Che Guevara, Pe. Juarez Benicio, Rui Gomes Dantas, etc.

1969 Jan (1 $\left.{ }^{\circ} \mathrm{Gpt} \mathrm{E}\right)$ : Em Of n9 12-E/2, de 16 Jan 69, o Cmt da Gu comunicou ao Reitor da UFPB, em resposta aos Ofs. n9s 01 e 02/GAB, daquela Reitoria que o Prof. JACKSON não possuía condições ideológicas necessárias para continuar como Professor.

1969 (Informe E/2): Em 29 Jan 69, o Pe. JACKSON, sabedor de que seu contrato de professor não seria renovado pela Reitoria, compareceu ao QG/12 Gpt E, e entre outras coisas: relatou os seguintes fatos: $\mathrm{Na}$ ocasião da invasão da $\mathrm{FaFi}$ ou outro qualquer movimento sempre procurou afastar-se, nunca teve qualquer atitude ativa nos movimentos estudantis, assembleias; jamais tendo feito qualquer comentário sobre assuntos políticos. Negou-se a assinar vários manifestos de caráter político, distribuídos pela Arquidiocese da PB; jamais usou o púlpito das igrejas para fazer manifestações políticas; uma das poucas conferencias que fez foi no I/15Q RI,a convite do Capelão daquela Unidade, em 1967,tendo falado sobre o tema "DOUTRINA SOCIAL DA IGREJA"; Negou ter comparecido a FaFi, juntamente com o Pe. JUAREZ, para levar aos estudantes a mensagem de solidariedade do clero progressista. Por ocasião da passeata estudantil de out/68 estava assistindo a mesma, na Praça do Bispo, juntamente com o Pe. TRIGUEIRO e quando surgiu a confusão refugiou-se no Palácio do Bispo. Quanto às suas relações com o Bispo não são muito boas por negar-se participar de certos atos, como podem testemunhar vários padres desta Capital. Por ocasião da greve de 68 na realmente esteve assistindo a assembleias estudantis, mas não tomou participação ativa. Outras fontes idôneas, ouvidas a respeito da conduta do Pe. Jackson, confirmaram que o mesmo é esquerdista.

Dados existentes nos arquivos desta AESI/UFPB: Intelectual. Apóia integralmente todo movimento esquerdista, ora em ação em todo Brasil. Disse em um Colégio de Freiras que o Julião devia ser condecorado como herói nacional. Está afastado da Universidade. Há notícias de que solicitou afastamento do clero e vai casar-se em São Paulo. Deu demonstração de apoio aos esquerdistas, por ocasião das crises na Fac. de Filosofia. O Reitor nunca lhe ofereceu função na Universidade após o seu afastamento. Of.nQ08-GAB-Impedido de lecionar no Inst. Central de Filosofia e Ciências Humanas/UFPB.

198017 Jun (ASI/UFPB): Afastado por ato da Reitoria e revertido ao cargo de Professor Titular pela própria, em 1979.

198009 set (ASI/UFPB): Nomeado Pró-Reitor de Graduação desta Universidade solicita informações à ASI/UFS.

198022 set (ASI/UFS): Em resposta ao PB acima, a ASI/UFS informa: "Reporto-me a Infão n9 73/73 dessa ASI de 24 MAI 73, na qual consta ter sido referido professor excluído do cargo "por falta de condições ideológicas para continuar exercendo o magistério". Cogitado recentemente para PM-REITOR DE PÓS-GRADUAÇÃO E PESQUISA (POSGRAD) desta UFS, obtivemos como resposta o Retemec n9 1143/83/25805/60/ DSI/MEC de 08 SET 80 - "Existem restrições". Exerceu as funções de "Gerente de Recursos Humanos" desde 28 JUN 78, tendo sido contratado como Professor Regente em 06 ABR 71, lecionando Didática Geral nesta Universidade." ${ }^{33}$

Em entrevista concedida ao Projeto História da UFPB/NDIHR, em setembro de 1990, José Jackson Carvalho foi questionado pelo fato de já ter sido considerado "subversivo" pelos órgãos de repressão $e$ ter sido eleito reitor com apoio das forças de direita, ao que respondeu:

Primeiro, eu nunca me considerei subversivo, eu nunca tive uma atuação política mais forte, nem no meio da universidade, nem fora da universidade. Eu acho que eu me considero, me considerei e me considero, uma pessoa, vamos dizer assim, que tem uma percepção, um certo compromisso com os movimentos sociais e jamais na minha vida eu assumi posições ao lado de quem oprimia. Eu tenho essa consciência. ${ }^{34}$

\footnotetext{
${ }^{33}$ ARE ACE CNF 1630/81. Fundo SNI. Arquivo da Comissão da Verdade...

${ }^{34}$ FERREIRA; FERNANDES. UFPB 50 Anos..., p. 109.
} 
Além dos reitores, a vigilância se dava também com os indicados para o cargo de Pró-Reitor, principalmente se este tinha uma trajetória ligada ao campo da esquerda. É o caso do professor Ruy Dantas, que foi afastado da UFPB, em 1968, voltou em 1979 com Lei de Anistia e em 1984 foi indicado pelo reitor José Jackson Carvalho para o cargo de Pró-Reitor de Assuntos Comunitários (PRAC). Logo após sua indicação, circulou pelos órgãos de informação seu prontuário, relatando todas suas ações no âmbito da UFPB e em outros espaços públicos:

196916 Jan (19 GPT E OF. N912-E/2): Em resposta ao Oficio n 9 01/69GAB/UFPB, de 04/01/69, o Cmt do 19 Gpt E informa ao Magnífico Reitor o seguinte: "julga Comando da Guarnição, após criterioso trabalho de nossa Seção de Informações, que o professor em pauta não possui condições ideológicas para continuar como principal responsável pela formação de nossos jovens, além de haver contribuído consideravelmente para a agitação estudantil no meio universitário no ano recém findo.

$196915 \mathrm{Fev}$ (SSI/UFPB): Em resposta ao Oficio n' 39-SNI/NAJP, de 12/02/69, informa o seguinte: professor contratado do Instituto de Filosofia e Ciências Humanas/UFPB. Seu contrato foi rescindido em 31/dez/68, por motivos de ordem política e falta do cumprimento do dever, no Magistério.

197109 Jul (1 9 GPT E INFAO N9231-E/2): Subscreveu, juntamente com outros elementos, um manifesto do "Ação, Justiça e Paz", Seção de João Pessoa, condenando a prisão dos estudantes em SÃO PAULO e manifestando solidariedade ao movimento estudantil. (Artigo publicado no jornal "CORREIO DA PARAÍBA", edição de 16 Out 68).

$197819 \mathrm{Jul}$ (DPF/PB INFÃO N9109): Em resposta ao oficio acima, aquela A.I. informa que sobre RUI GOMES DANTAS, sem dados qualificativos, existe o seguinte registro: juntamente com outros elementos, assinou uma nota publicada na imprensa local em 15/10/68, apoiando um movimento do clero contra atitudes governamentais. 197829 Nov (DSI MEC): Em resposta ao PB acima, a DSI/MEC informa que existem restrições quanto ao aproveitamento do nominado.

198017 Jun (ASI/UFPB): Afastado por ato da Reitoria e revertido ao cargo de Professor Titular pela própria, em 26.11.79.

198016 Jun (ASI UFPB): Participou ativamente dos debates realizados no dia 11 Jan. 80, nesta UFPB, por ocasião do "DIA NACIONAL DE PROTESTO DA ADUFPBJP", sendo um dos articuladores do movimento de paralisação das aulas. No dia 25.06.80, no auditório da Reitoria, participou ativamente do Tumulto promovido pela ADUFPB, em protesto pela realização das eleições para escolha da lista sêxtupla dos candidatos a Reitor/UFPB.

198002 Set (ASI UFPB): a Assembleia Geral realizada pela ADUF/PB no dia 28.08.80, onde o principal objetivo foi decidir a deflagração do movimento grevista para obrigar a Reitoria a reintegrar no quadro de docentes a professora SONIA MARIA TADDEI FERRAZ, afastada por força de decisão da Justiça Federal, o nominado participou ativamente, considerando o ato de afastamento da professora como arbitrário e violento, por parte da Reitoria.

198025 nov (ASI/UFPB): N: Assembleia Geral da ADUF-JP, realizada no dia 19 nov 80, foi eleito suplente do COMANDO GERAL DA GREVE.

198118 maio (ASI/UFPB): No dia 15. 05. 81 o Reitor da UFPB reuniu o Conselho do CCHLA para comunicar a nomeação do prof. ARAEL MENEZES DA COSTA, para Diretor "Pró-Tempore" do CCHLA. A finalidade da reunião era esclarecer aos membros do Conselho os motivos que levaram o MEC a nomear o referido professor. $\mathrm{Na}$ ocasião, foi lida a NOTA OFICIAL do Reitor a respeito da nomeação. Não acatando os esclarecimentos do Reitor, juntamente com o prol. FRANCISCO PEREIRA NÔBREGA, em nome da maioria dos membros dc Conselho, declarou que não concordava com a nomeação do prof. ARAEL e, portanto, não reconheceria sua autoridade.

198119 maio (ASI/UFPB): Dando cumprimento ao decidido na Assembléia Geral de professores do CCHLA, realizada no dia 15.05.81. juntamente com o presidente da ADUFPB-JP, o vice-presidente regional da ANDES, o presidente da ADUFPB/JP e o presidente do DCE, subscreveu e entregou um documento ao prof. ARAEL MENEZES 
DA COSTA, recém-nomeado Diretor do Centro, solicitando a renúncia do mesmo até o dia 20.05.81, como "única forra de honrar o seu compromisso anteriormente assumido com as práticas democráticas existentes na UFPB".

198205 julho (ASI/UFPB): No dia 22.06.82, em eleição realizada no CCHLA, para escolha de seus docentes representantes, foi eleito TITULAR junto ao CONSELHO UNIVERSITÁRIO pela chapa apoiada pela ADUPPB-JP.

198310 out (ASI UFPB): Coordenador de Mestrado em Filosofia da UFPE. Integrante da Comissão Organizadora do 1 SEMINÁRIO DE FILOSOFIA DO NORDESTE, que será realizado no auditc5/ 1 ;io de Espaço Cultural "JOSÉ LINS DO REGO", nesta capital, no período de 13 a 16 de outubro de 1983. A promoção do seminário, que discutira o tema: MARX - Uma Avaliação Contemporânea, é da Sociedade de Estudos e Atividades Filosófica. (Regional-Nordeste) e do Mestrado em Filosofia da UFPB, com apoio da CAPES, CNPq e Reitoria da UFPB. No dia 16, como coordenador, participara da Mesa Redonda sobre Dialética e Teologia da Libertação. ${ }^{35}$

Em depoimento à Comissão da Verdade e Preservação da Memória do Estado da Paraíba, o professor Ruy Dantas relata como era sua atuação como professor da instituição:

Bem, eu ingressei como professor na Universidade Federal da Paraíba em primeiro de março de mil novecentos e sessenta e seis após ter sido aprovado em concurso público para área de filosofia, para lecionar na Faculdade de Filosofia Ciências e Letras da UFPB. Na antiga FAFI lecionei de sessenta e seis a final de sessenta e oito várias disciplinas, Metafísica, Teoria do Conhecimento, Filosofia das Ciências, algumas das Histórias da Filosofia não me lembro bem se Filosofia Grega, Filosofia Moderna. Durante o período de sessenta e seis a sessenta e oito sempre mantive uma posição crítica em relação ao regime militar que se instaurou no país desde 1964. No exercício da cátedra, exerci sempre com ousadia até demasiada por vezes, a liberdade de pensamento inerente e essencial à atividade acadêmica, sobretudo na minha área de docência, a Filosofia. Opondo-me à então vigente ideologia da segurança nacional que vigorou durante todo o período do regime militar, ideologia de segurança nacional gestada na escola superior de guerra sobre inspiração do General Golbery do Couto e Silva famoso General Golbery. Durante este período todo, claro que eu era bem mais jovem, e portanto muito mais ousado do que ainda sou hoje, pronunciei conferências, participei de debates públicos e de manifestações públicas nos quais expressei meu pensamento crítico em relação ao regime político que vigorava. Dos (inaudível) (...) de 1968, quando recrudesceu a ditadura militar emprestei decididamente meu apoio ao emergente movimento estudantil que tomou conta das ruas de João Pessoa e de todo o território nacional denunciando as arbitrariedades do regime militar ditatorial e reivindicando o retorno da democracia. Além disso, durante aqueles anos sessenta $e$ seis a sessenta $e$ oito participei de diversas ações $e$ iniciativas da Arquidiocese da Paraíba sob a liderança do arcebispo, do eminente arcebispo Dom José Maria Pires, atividades estas especialmente enfocadas na defesa dos direitos humanos, cheguei mesmo a dirigir o Centro de Defesa dos Direitos Humanos da Arquidiocese da Paraíba. Com o Ato Institucional número 5 de treze de dezembro de 1968, intensificou-se a perseguição política a todos os brasileiros que se insurgiram contra o regime militar, em especial aos membros da comunidade universitária, sem que lhes fosse dado se quer o direito ao devido processo legal, a ampla defesa e ao contraditório. ${ }^{36}$

Em seguida, ele narrou também como seu deu seu processo de demissão da UFPB e seu retorno, após a Lei da Anistia, de 1979:

Bem aconteceu que, no dia primeiro de fevereiro, já no final de mil novecentos e sessenta e oito, eu li nos jornais a minha expulsão da Universidade Federal da

\footnotetext{
${ }^{35}$ ARE ACE CNF 1630/81. Fundo SNI. Arquivo da Comissão da Verdade...

${ }^{36}$ Depoimento dado na Audiência Pública da Comissão da Verdade e Preservação da Memória do Estado da Paraíba, em 27/03/2015. Arquivo da Comissão da Verdade e Preservação da Memória do Estado da Paraíba. Fundação Casa de José Américo.
} 
Paraíba, fui tomar café no Ponto de Cem Réis e li pelo jornal. Nada havia ainda de oficial, a minha atitude foi de viajar para Recife, onde residia os meus pais e irmãos (...) Mas foi no dia primeiro de fevereiro de mil novecentos e sessenta e nove que por intermédio do ofício reservado número três SSI barra sessenta e nove, do Serviço de segurança e Informação da UFPB, foi nesse dia que o então reitor, reitor interventor, Guilardo Martins Alves, interventor porque foi colocado no lugar do grande jurista $e$ grande intelectual, aliás colega de turma de meu pai e amigo do meu pai, Mario Moacyr Porto então Guilardo Martins Alves comunicou às autoridades militares uma série de "providências" no intuito de "ser fiel aos ideais e à continuidade do processo revolucionário". Dentre essas providências, providência, aspas, a contratação não renovada do professor Ruy Gomes Dantas e de outros professores de diversas faculdades da universidade (...) Bem, na verdade, eu pessoalmente só vim a ter conhecimento desse oficio e do meu afastamento nos quadros do magistério da Universidade Federal da Paraíba no dia 5 de fevereiro de 1969, através de um oficio da coordenadora do instituto central de filosofia e ciências humanas, Vilma dos Santos Cardoso Monteiro comunicando que o meu contrato com UFPB "não mais será renovado por determinação da reitoria da Universidade Federal da Paraíba" o oficio dela (...) carimbo diz: "Senhor professor cabe a esta coordenação informar que por determinação da reitoria da Universidade Federal da Paraíba o contrato com vossa senhoria não mais será renovado, atenciosas saudações' (...) Então, em virtude da lei da anistia, tendo como fundamento essa lei, fui reintegrado aos quadros da Universidade Federal da Paraíba, em 15 de fevereiro de 1980, através de portaria assinada pelo vice reitor (...) em exercício, professor Serafin Rodrigues Martins, homem muito digno, que resolveu fazer, cito a portaria: 'Retornar Rui Gomes Dantas ao serviço público federal no emprego de professor titular'. ${ }^{37}$

O professor Itan Pereira da Silva foi nomeado no dia 30 de novembro de 1984, para o cargo de Pró-Reitor para Assuntos do Interior. De imediato, a ASI-UFPB faz circular, por meio do SNI, informações sobre a trajetória política e acadêmica do mesmo:

23 de julho 1968 (4 $4^{\mathrm{a}} / 14^{\circ} \mathrm{RI}$ Info): Em relatório sob o título "Campanha subversiva em CAMPINA GRANDE-PB", caracterizada pelo surgimento de vários panfletos $e$ boletins nos meses de maio, junho e julho e por concentrações estudantis e operários, após a citação de que "a organização principalmente comprometida foi o Comitê Municipal do Partido Comunista", consta: -"Convém ajuizar que essas manifestações foram fruto também da Ação Popular (AP) e do clero. No Clero destacam-se, principalmente: (...) e Padre ITAN PEREIRA DA SILVA.

196804 Out (4-/149 RI Info): Em 1968, juntamente com outros padres de CAMPINA GRANDE, liderou o movimento "AÇÃO, JUSTIÇA E PAZ" lançado em várias cidades brasileiras pelo Arcebispo de Olinda e Recife, Dom HELDER CÂMARA (Anexo: Cópia do Artigo publicado no jornal "Diário da Borborema", edição de 04 Out 68).

1971 Jul 06 (AESI/UPPB): Candidatou-se a uma cadeira de professor no Instituo Central de Filosofia e Ciências Humanas (ICFCH). A diretora do Instituto, tendo em vista seus antecedentes, procurou manter um entendimento com e mesmo para comunicar que iria indeferir seu requerimento. $\mathrm{Na}$ oportunidade, o Padre ITAN solicitou um prazo de tolerância, com a finalidade de ir a CAMPINA GRANDE solicitar a seus amigos militares uma neutralização de seus antecedentes.

197103 Ago (1 ${ }^{\circ}$ Gpt e Info): No dia 03 Ago 71 apresentou nesta QG uma exposição sobre sua vida pregressa, com o objetivo de esclarecer fatos registrados sobre o mesmo, de modo a ficar isento de qualquer suspeita de atividades contrárias ao regime ou aos princípios da Revolução de março de 1964. Em consequência foram acionados os órgãos de busca da área. Em resposta o 1/159 RI, a 232 CSM, a Capitania dos Portos/PB, o DF/PB e a SSP/PB informaram nada constar em seus respectivos arquivos. A 52 Cia. sediada em CAMPINA GRANDE-PB, confirmou as informações já registradas neste prontuário ocorridas com o nominado naquela cidade, no ano de 1968. Assessoria Especial de Segurança e Informações da Universidade Federal da Paraíba e (AESI/UFPE) informou: ITAN PEREIRA DA SILVA

\footnotetext{
${ }^{37}$ Depoimento dado na Audiência Pública da Comissão da Verdade...
} 
estuda em Roma, já no curso superior. Figurava como Padre da linha avançada Vaticano II. Tido como inteligente e admirador do Arcebispo D. HELDER, sendo um forte adepto deste. Atualmente leciona na FURNE, em CAMPINA GRANDE. Tentou Inclusão na Universidade Federal da Paraíba, mas teve seu requerimento indeferido pela Direção do Instituto Central de Filosofia e Ciências Humanas.

197101 Dez 19 (Gpt E Info 497 e 498-E/2): 01 Dez. Solucionando a Exposição apresentada neste QG o Exmo. Sr. Cmt 19 Gpt E deu o seguinte despacho: "Remetase cópia de sua exposição aos órgãos que possuem registro de antecedentes a seu respeito, para que sejam levados na devida conta, quando necessário, a critério do respectivo Órgão".

197208 Fev (FACE/CG FCECG/GD/ OF.0072): Candidato aprovado pelo Departamento de Ciências Sociais da FACE/C.GRANDE para ministrar aulas em disciplinas do Ciclo Básico (Áreas de Português, Inglês e Metodologia das Ciências) solicita informações sobre o marginado.

$197218 \mathrm{Fev}$ (FACE/CG FCECG/GD/ OF/0086): Encaminha esclarecimentos suplementares sobre o nominado: Diretor do Colégio PIO XI, Professor da Universidade Regional do Nordeste (URN) e Professor a título precário da FACE/CC.

197207 Mar (AESI/UFPB Info n9 34): Diante da informação prestada pela AESI ao Diretor da FACE/C.GRANDE, o interessado tentou rever o problema. Em consequência, o Assessor deu conhecimento do fato ao Reitor, entregando-lhe o Prontuário do evidenciado para solução definitiva. Após entendimento mantido pelo Reitor com o Gen Cmt da Guarnição, foi decidido manter a RESTRIÇÃO.

197225 Mai (AESI/UFPB Info n995): O Magnifico Reitor da UFPB considerando os termos do Oficio n9 87-E/2-Confidencial, de 15 mai 72, do Cel GENTIL NOGUEIRA PAES, Chefe do Estado-Maior/19 Gpt. Em consequência, e mais, pela predisposição declarada neste QG pelo Pe. ITAN de trabalhar afinado com os ideais da Revolução/64, aliado ao fato de o mesmo já vir lecionando há mais de um ano com plena normalidade, expressa a Vossa Magnificência o parecer deste Comando de que, a critério dessa Reitoria, pode ser dada uma oportunidade ao mesmo de reafirmar-se no campo do ensino, como deseja e pelo que vem tenazmente lutando, resolveu dar uma oportunidade ao evidenciado, devendo no entanto, ser exercida total fiscalização no desempenho de suas atribuições junto àquela Unidade, após contratação se for o caso.

197206 Dez (DP/UFPB CONTRATO/ TRABALHO): Com vigência a partir de 19 de janeiro de 1973, foi contratado pela UFPB, pelo regime da CLT, para exercer o cargo de Professor Titular junto ao Departamento de "Ciências Sociais" da Faculdade de Ciências Econômicas de CAMPINA GRANDE (FACE/CG).

198106 Ago (CH/UFPB): O Diretor do Centro de Humanidades de CAMPINA GRANDE comunica ao Diretor do Departamento de Pessoal/UFPB que o nominado tomou posse no cargo de Vice-Diretor do referido Centro, em cumprimento de Portaria N9 339, de 08.05.81, do Sr. Ministro da Educação e Cultura.

1981 (DF/UFPB/ Port. R/DP/ N9 961): Foi designado pelo Reitor da UFPB para exercer o cargo de Coordenador de Coordenação Setorial de Assuntos Comunitários da Pró-Reitoria para Assuntos do Interior, a partir de 19 de julho de 1981.1984 (DP/UFPB/Port. R/DP/ N9 641): Foi designado pelo Reitor da UFPB para exercer o cargo de confiança de Pró-Reitor para Assuntos do Interior, a partir de 30 novembro de $1984 .^{38}$

Então, percebe-se, tanto o SNI quanto a ASI-UFPB, mesmo no período da chamada "transição lenta, gradual e segura", colocando sob suspeita - devido a sua trajetória de vida e relações com a Igreja Progressista ou com outros professores considerados esquerdistas - dirigentes universitários, escolhido dentro das regras estabelecidas pela própria universidade e aceitas pelo Ministério da Educação.

Outra grande preocupação dos Órgãos de Informações (OIs) era quanto a influências dos partidos de esquerda, nas associações representativas das categorias da universidade, tanto de professores, funcionários e estudantes, e também na capacidade destes de eleger professores para os cargos de chefes de departamento e coordenadores de curso. No campus da II da UFPB, localizado na cidade de

\footnotetext{
${ }^{38}$ ARE ACE CNF 1630/81. Fundo SNI. Arquivo da Comissão da Verdade...
} 
Campina Grande, eles destacam a influência do Partido Comunista do Brasil (PC do B), do Movimento Revolucionário (MR-8) e da Ala Prestes do Partido Comunista Brasileiro (PCB), nas eleições para esses cargos:

Quanto ao meio estudantil, se tem o seguinte:

1. No meio estudantil, mais precisamente na UFPB Campus II, o MR-8 tem ao seu dispor o DEPARTAMENTO DE ECONOMIA e o MESTRADO EM ECONOMIA RURAL, chegando, juntamente com o PCB ala Prestes e do PC do B, a reeleger para coordenador desse último, o sr. Reinaldo Carcanholo, conhecido terrorista na década de 70. E para vice-coordenador foi eleito o radical PAULO NAKATAN, do Departamento de Economia.

2. As eleições na UFPB CAMPUS II para cargos de direção são feitas fugindo aos critérios estabelecidos na chamada lista sêxtupla, visando tão somente atender aos objetivos de militantes e simpatizantes de organizações subversivas, como vemos a seguir:

3. SEBASTIÃO VIEIRA GUIMARÃES, segundo colocado na lista, foi eleito vicereitor com apoio das diversas organizações esquerdistas que atuam dentro da Universidade. Recebe o apadrinhamento de Lynaldo Cavalcante de Albuquerque, atual Presidente do Conselho Nacional de Desenvolvimento Científico e Tecnológico (CNPq).

4. ITAN PEREIRA DA SILVA, ex padre, foi eleito diretamente, sem lista sêxtupla, pró-Reitor da PRÓ-REITORIA de Assuntos do Interior. Trata-se de um elemento liberal e comprometido com a esquerda. Em sua carta à comunidade universitária da UFPB, já defende a existência, dentro da própria universidade, de espaços para as diferentes concepções de ordem política, ideológica etc. de grupos ou pessoas sem distinções ou preconceitos que obstruam posições ou ideias.

5. Para o CENTRO DE HUMANIDADES foi eleita Albanita de Tal para diretoria e Cristina de Tal para vice-diretora, a qual é também comprometida com as organizações subversivas, com probabilidade, inclusive, de ditar normas e impor condições dentro do referido CENTRO.

6. LENILDA NASCIMENTO, ex Diretora do CENTRO DE HUMANIDADES, esquerdista, foi nomeada para pró-Reitora de graduação da já referida universidade, que facilitará em muito a atuação das organizações subversivas.

7. As eleições dos coordenadores dos mestrados e Economia e Sociologia Rural, além de terem sido processadas de maneira fraudulenta, os elementos eleitos estão igualmente comprometidos com a esquerda. Inclusive, está prevista para o MESTRADO de 1985 a substituição de algumas disciplinas optativas por aulas de doutrinação marxista. ${ }^{39}$

De fato, essas organizações da esquerda clandestina citadas, passaram a ter uma presença forte no movimento estudantil e, também no meio docente, principalmente depois da diminuição de critérios ideológicos para contratação de professores, iniciado no reitorado de Lynaldo Cavalcanti, o que levou a uma maior pluralidade intelectual no meio acadêmico. Esta postura dos Órgãos de Informações de denúncia do "perigo comunista", faz parte dos valores dos agentes e dos próprios militares que implantaram a ditadura. Segundo Motta,

Por falar nos valores dos agentes de informação, é importante destacar o papel ocupado pelo anticomunismo, componente-chave nos discursos e motivações dos grupos que apoiaram o golpe de 1964, tanto militares quanto civis. Entre os militares, o imaginário anticomunista teve importância particular, constituindo recurso para unir a corporação ao mobilizar sentimentos nacionalistas e patrióticos arraigados no ambiente castrense. De acordo com a visão militar, lutar contra o comunismo era defender a pátria contra a ameaça estrangeira, tradição iniciada com a repressão ao movimento revolucionário de 1935, a chamada Intentona Comunista. Assim, quando os militares falavam em defender a segurança nacional e em combater a guerra revolucionária, a principal ameaça respondia pelo nome de comunismo, e parte das políticas adotadas pela ditadura foi influenciada por esse mote. Isso aplica não apenas

\footnotetext{
${ }^{39}$ ARE ACE CNF 1630/81. Fundo SNI. Arquivo da Comissão da Verdade...
} 
ao terreno da segurança e dos expurgos, mas também nas áreas cultural e educacional, que os agentes do regime militar imaginavam particularmente suscetíveis às ações comunistas. ${ }^{40}$

Como podemos ver, os Órgãos de Informação (OIs) da ditadura militar mantiveram constante vigilância sobre os dirigentes universitários e, em alguns casos, conseguiram vetar contratações de indicados. Segundo Motta,

(...) os OIs também escrutinavam os nomeados para cargos como reitor, diretor, chefe de departamento e coordenador de curso (e respectivos vices). De acordo com entrevistas e documentos oficiais, muitos docentes foram impedidos de assumir esses cargos, em diversas universidades. ${ }^{41}$

\section{Considerações finais}

Com a ditadura militar instalada no Brasil em 1964, um amplo sistema de vigilância foi montado contra a sociedade civil e órgãos do Estado com a criação do SNI. Mas havia diferenças entre este órgão e o sistema de repressão representado pelo sistema DOI-CODI. Como destaca Fico,

Fundamentalmente um produtor de informações, é provável, não obstante, que o SNI tenha participado de "operações de segurança", isto é, de prisões e interrogatórios que tantas vezes lançavam mão de tortura. Mas havia uma distinção entre os órgãos de informações, integrantes do Sisni, e os de segurança. Assim, ao contrário do que já se supôs, o SNI não foi o "órgão de segurança por excelência" - definição que cabe melhor ao sistema Codi-DOI -, nem subordinou "todos os outros órgãos repressivos", já que os órgãos de informações dos ministérios militares e, sobretudo, os Codi-DOI, não eram controlados pelo Serviço. Essa é uma distinção importante, necessária a uma compreensão mais refinada da história do período, pois muitas vezes se tem englobado na expressão "porões da ditadura" instâncias muito diversas. O que se fazia numa DSI diferia muitíssimo daquilo que se passava num DOI. Um agente de informações, civil ou militar, que trabalhasse numa DSI, nada tinha a ver com a atividade de capitão que atuasse numa "turma de interrogatório" do DOI. O primeiro fazia escutas telefônicas, recortava jornais, redigia avaliações. ${ }^{42}$

No entanto, "não se quer propor que tais atividades fossem completamente desconexas, até porque o Sisni foi criado precisamente para subsidiar, com informações, as atividades da repressão (e não para fornecer relatórios à presidência)". ${ }^{43}$

O SNI atuava em todo território nacional, e no caso do estado Paraíba, através da Agência Pernambuco. Como vimos, na UFPB, o Serviço desenvolveu a vigilância, em parceria com a ASI, sobre toda comunidade acadêmica, até mesmo e sobre os dirigentes universitários, colocando todos sob suspeita, inclusive pessoas como o reitor Lynaldo Cavalcanti, que teve uma trajetória de apoio ao regime militar. Isto demonstra como esse órgão adquiriu uma autonomia muito grande, permitindo que seus agentes colocassem sob suspeição até mesmo aliados do regime.

\footnotetext{
${ }^{40}$ MOTTA. As universidades e o regime militar:.., p. 206-207.

${ }^{41}$ MOTTA. As universidades e o regime militar:.., p.235.

${ }^{42}$ FICO. Como eles agiam..., p. 177-178.

${ }^{43}$ FICO. Como eles agiam..., p. 178.
} 


\section{RESUMO}

Com o golpe civil-militar, uma das primeiras medidas de institucionalização do novo governo foi a criação do Serviço Nacional de Informação (SNI). O referido órgão foi criado formalmente pelo Decreto-Lei $n^{\circ}$ 4.341, de 13 de junho de 1964. Em 1970, o governo militar, visando aperfeiçoar o sistema de informações, institui o Sistema Nacional de Informações (SISNI). Este passou a ser integrado pelo Serviço Nacional de Informações (SNI), pelos "Sistemas Setoriais de Informações dos Ministérios Civis", pelos "Sistemas Setoriais de Informações dos Ministérios Militares", pelo "Subsistema de Informações Estratégicas Militares" (SUSIEM) e por outros órgãos setoriais. O que o SISNI entendia como "Outros Órgãos Setoriais de Informações" eram assessorias de informações situadas em importantes esferas da administração pública ou em empresas estatais. Este texto analisa a produção de informações feitas ou difundidas pelo Serviço de Nacional de Informações (SNI) referentes a membros da comunidade acadêmica da Universidade Federal da Paraíba (UFPB), com ênfase nos dirigentes universitários.

Palavras-chave: História política; Ditadura militar; Comunidade de informações.

Artigo recebido em 07 ago. 2018.

Aprovado em 11 set. 2018. 
